\title{
NUEVAS LEYES, MISMOS PROBLEMAS: LA ENSEÑANZA DE LA HISTORIA EN ESPAÑA A PARTIR DE LOS RECUERDOS DE LOS FUTUROS PROFESORES DE EDUCACIÓN SECUNDARIA
}

\author{
New laws, Same Problems: History Teaching in Spain Through \\ the Memories of Future Secondary School Teachers
}

\author{
Sebastián Molina Puche \\ smolina@um.es \\ Universidad de Murcia. España \\ Jorge Ortuño Molina \\ jortunom@um.es \\ Universidad de Murcia. España \\ María Sánchez Agustí \\ maria.sanchez.agusti@uva.es \\ Universidad de Valladolid. España \\ Fecha de recepción: 08//04/2021 \\ Fecha de aceptación: 01/06/2021
}

Resumen: Desde 1970, en las diferentes leyes generales de Educación se ha orientado al profesorado de Ciencias Sociales a asumir planteamientos innovadores, encaminados a conferir mayor practicidad a su acción docente. Desde esta perspectiva, este artículo se plantea analizar las visiones de los futuros profesores de Historia y Geografía sobre los métodos de enseñanza, indagando en el pasado disciplinar a través de su memoria como discentes. El estudio se ha realizado en las Universidades de Murcia y Valladolid, en la especialidad de Geografía e Historia del Máster de Formación del Profesorado durante el curso 2020/2021, con un total de 55 participantes. El diseño de investigación se corresponde con un enfoque cualitativo y para la obtención de datos se ha utilizado un cuestionario abierto. Las narrativas resultantes han sido analizadas inductivamente con el software 
Nvivo. Los resultados recogen que, aunque hay algunas diferencias según el marco legislativo en el que se cursó la ESO, la mayoría de los participantes guarda recuerdos negativos de su experiencia como alumnos de geografía e historia, ligados a métodos docentes tradicionales como la lección magistral, el dictado de apuntes, el uso del libro de texto y la práctica ausencia del fomento del pensamiento crítico. De ahí que la clave para una auténtica transformación en la metodología docente parece estar más en una buena formación inicial, así como en una revisión de la extensión de los contenidos curriculares, que en el cambio de las leyes generales de educación.

Palabras clave: Educación histórica; Enseñanza de las Ciencias Sociales; Educación Secundaria; Metodología docente; Concepciones del profesorado.

Abstract: Since 1970, in the different general education laws, social sciences teachers have been oriented to assume innovative approaches, with the aim of enhancing applied elements in their teaching practice. From this perspective, this article sets out to analyze the views of history and geography trainee teachers on teaching methods, investigating the disciplinary past through their memory as learners. The study was carried out at the universities of Murcia and Valladolid, with a total of 55 participants enrolled at the specialty of geography and history of the Master's Degree in Teacher Training during the 2020/2021 academic year. The research design assumed a qualitative approach, and an open questionnaire was used to obtain data. The resulting narratives were inductively analyzed with the Nvivo software. The results show that, although there are some differences according to the legislative framework in which the ESO (compulsory secondary education) was studied, most of the participants have negative memories of their experience as geography and history students. This was found to be linked to traditional teaching methods such as expository classes, the dictation of notes, the use of the textbook, and the practical absence of the promotion of critical thinking. Hence, the key to an authentic transformation in teaching methodologies seems to lie more in an effective initial training, as well as in a revision of the extension of the curricular contents, than in the changes of the general education laws.

Keywords: History Education; Teaching of Social Sciences; Secondary Education; Teaching methodology; Conceptions of teachers.

Sumario: 1. Introducción: la legislación educativa española. Del sosiego al sprint. 2. La orientación para la acción docente en Historia y Ciencias Sociales en las directrices legislativas. 2.1. La renovación de la enseñanza de las Ciencias Sociales en la legislación (1970 - 2000/2002). 2.2. El galopar legislativo y su repercusión en la enseñanza de las Ciencias Sociales (del 2000-2002 al 2020). 2.3. Muchas reformas, ¿pocos resultados? La percepción de alumnos y docentes. 3. Marco empírico. 3.1. Diseño de la investigación. 3.2. Instrumento de recogida de datos y procedimiento de análisis. 4. Análisis de resultados: los recuerdos sobre la experiencia como discente de CCSS en etapas educativas obligatorias. 5. Discusión. 6. Conclusiones. 7. Referencias bibliográficas. 


\section{INTRODUCCIÓN: LA LEGISLACIÓN EDUCATIVA ESPAÑOLA. DEL SOSIEGO AL SPRINT}

En el momento en que este monográfico ve la luz, una vez más la educación española se ve inmersa en un cambio legislativo ${ }^{1}$, aunque todavía no ha sido publicado el consiguiente Real Decreto que ha de establecer el currículo de las materias de la Educación Secundaria, de acuerdo con la ley orgánica recién aprobada. No sabemos, por tanto, las modificaciones que la nueva normativa pueda aportar a la enseñanza de la geografía y la historia. Y de igual manera desconocemos si sus contribuciones a la metodología didáctica van a suponer un cambio sustancial a lo propuesto en legislaciones anteriores, y van a poder dar respuesta a las necesidades que el profesorado de Ciencias Sociales ha expuesto reiteradamente en los últimos años. Dar cuenta de ello, si bien sea en una somera descripción, es la razón de los epígrafes que siguen, como preámbulo para enmarcar y explorar la memoria almacenada por los profesores de ciencias sociales en formación inicial sobre la acción docente recibida en sus años de escolarización obligatoria.

Para iniciar este recorrido podemos considerar la educación española, en la Edad Contemporánea, organizada en dos amplios periodos. El primero, abarca 113 años, nada menos que desde 1857 a 1970, periodo de vigencia de la llamada «Ley Moyano ${ }^{2}$, que estableció, al menos teóricamente, la enseñanza obligatoria de los estudios primarios, hasta que fue derogada, después de más de un siglo de vigencia, por la Ley General de Educación también llamada «Ley Villar Palasí»». La LGE de 1970 fue un positivo hito divisorio trascendental, porque acabó con un sistema que pervivía durante más de un siglo, fundamentado en la inequitativa duplicidad de dos fórmulas de educación paralelas e inconexas: la educación primaria superior que se enseñaba en las escuelas (9-12 años) y el bachillerato que se impartía en los institutos de enseñanza media (10-16 años). La nueva ley generalizó la misma educación básica y general para todos, de 6 a 14 años, y estableció los métodos, instalaciones y características de una educación moderna.

El segundo periodo comprende cincuenta y un años y viene transcurriendo desde 1970 hasta nuestros días. Pero este segundo periodo puede dividirse también en dos:

${ }^{1}$ Ley Orgánica 3/2020, de 29 de diciembre, por la que se modifica la Ley Orgánica 2/2006, de 3 de mayo, de Educación, aprobada recientemente viene a sustituir a la LOMCE hasta ahora vigente.

${ }^{2}$ Ley de Instrucción Pública. Gaceta de Madrid núm. 1710. 10 de septiembre de 1857. https://www.boe.es/datos/pdfs/BOE/1857/1710/A00001-00003.pdf

${ }^{3}$ Ley 14/1970, de 4 de agosto, General de Educación y Financiación de la Reforma Educativa. https://www.boe.es/boe/dias/1970/08/06/pdfs/A12525-12546.pdf 
- Un subperiodo crucial que duró treinta años, de 1970 al 2000/2002, que puede ser calificado como de progresiva modernización del sistema educativo español. Primero a través de la aplicación de la Ley General de Educación de 1970 (LGE), cuya importancia estratégica fue tan potente que, siendo una ley franquista, se desarrolló y aplicó durante década y media de democracia, convirtiéndose en uno de los sectores concretos de aplicación de los «Pactos de la Moncloa». Y más adelante, en 1990, con la gestación de una importante Ley de Educación, la LOGSE$^{5}$, la ley que mayor repercusión ha tenido en la enseñanza secundaria, porque cambió la estructura del sistema educativo, partiéndolo en dos: una obligatoria, básica y general para todos los ciudadanos (6-16 años), y otra postobligatoria, el bachillerato (16-18 años). Siendo esta organización una de las pocas cosas que no se ha modificado desde entonces.

- Y un subperiodo de veinte años, del 2000/2002 al 2021, en el que se han aprobado nada menos que cuatro leyes orgánicas de Educación, es decir, una ley general cada poco más de cinco años, a pesar del loable intento del ministro socialista Ángel Gabilondo (2009-2011), para sacar adelante una ley educativa consensuada entre gobierno y oposición, sin que le fuese posible.

En todo caso, y ante los distintos cambios legislativos que, en los últimos años, se han sucedido de manera vertiginosa, el profesorado de Ciencias Sociales ha presentado una serie de reclamaciones que, en ocasiones, se repiten. Ante ello, resulta interesante constatar las principales características que, en el campo de las ciencias sociales, supuso cada una de estas leyes, a fin de comprobar el efecto que las mismas pudo tener en formación inicial del profesorado, y en su visión sobre las necesidades que tiene la enseñanza de la Geografía y la Historia.

\section{LA ORIENTACIÓN PARA LA ACCIÓN DOCENTE EN HISTORIA Y CIENCIAS SOCIALES EN LAS DIRECTRICES LEGISLATIVAS}

En los párrafos siguientes abordamos un repaso por las indicaciones y sugerencias pedagógicas que, en cada una de las sucesivas reformas educativas, se han entregado al profesorado de ciencias sociales, legitimando o no la persistente tradición metodológica que parece estar anclada en las aulas, basada en la explicación del profesor y la respuesta memorizada de los estudiantes como contrapartida. Para ello, excepto en el caso de la Ley General de $1970^{6}$, nos centraremos en la

${ }^{4}$ Puede consultarse el artículo publicado en El País con motivo de cumplirse los 40 años de su firma. https://elpais.com/politica/2017/10/20/actualidad/1508514039_177535.html

${ }^{5}$ Ley Orgánica 1/1990, de 3 de octubre, de Ordenación General del Sistema Educativo. BOE n.o 238 (4/10/1990). https://www.boe.es/boe/dias/1990/10/04/pdfs/A28927-28942.pdf

6 En la LGE la enseñanza básica y obligatoria llegaba solo hasta los 14 años y era responsabilidad de los maestros y maestras. 
normativa que regula la enseñanza secundaria obligatoria, al ser esta etapa la más necesitada de apoyatura didáctica y pedagógica y restringiremos, por falta de espacio, el análisis descriptivo a las normas estatales, prescindiendo de las autonómicas cuando las hubiere.

\subsection{La renovación de la enseñanza de las Ciencias Sociales en la legislación (1970 -2000/2002)}

Es muy interesante resaltar cómo, ya en la Ley General de Educación y de Financiamiento de la Reforma Educativa ${ }^{7}$ de 1970 (que tomamos como punto de partida por considerarla, como hemos dicho anteriormente, el hito de inicio de una educación moderna y general para todos los ciudadanos) aparecen indicaciones para renovar metodológicamente la enseñanza de las Ciencias Sociales.

En esta normativa la acción docente en el Bachillerato (15-17 años) se entiende «no como una enseñanza centrada exclusivamente en la explicación de la materia»; ya que «los métodos de enseñanza serán predominantemente activos». Estas indicaciones, junto con el hecho de que esta ley general establece por primera vez el requisito de que los docentes posean, junto con la licenciatura en la materia correspondiente, una formación pedagógica, hacía presumir una apuesta clara por la renovación de la tradición docente.

No obstante, basta con echar un vistazo al programa de las asignaturas, establecidas en la Orden de 22 de marzo de $1975^{\circ}$, para comprobar la gran dificultad de conciliar estos principios pedagógicos con unos programas exhaustivos que abarcan toda la historia. Así, en primer curso (14-15) la Historia de las Civilizaciones incorpora contenidos desde las culturas prehistóricas hasta la actualidad, y en el último curso, tercero (16-17), la Geografía e Historia de España y de los países Hispánicos se ocupa de todas las etapas históricas de nuestro país, enmarcadas con unas lecciones previas sobre el marco físico de la península lbérica y otras posteriores sobre cuestiones de geografía económica de España. A estas se une, como epílogo, un repaso sobre los principales países de cultura hispánica, incluido Filipinas.

No hay en estos programas ni una sola mención a la metodología docente propuesta en la propia Ley General. Y es que, como prueban los libros de texto de la época, su extensión no dejaba espacio temporal al aprendizaje activo y hacía difícil, incluso, utilizar la propuesta de actividades que, especialmente en la década de los

7 Ley 14/1970, de 4 de agosto, General de Educación y Financiación de la Reforma Educativa. https://www.boe.es/boe/dias/1970/08/06/pdfs/A12525-12546.pdf

${ }^{8}$ Orden de 22 de marzo de 1975 por la que se desarrolla el Decreto 160/1975, de 23 de enero, que aprueba el Plan de estudios del Bachillerato https://www.boe.es/boe/dias/1975/04/18/ pdfs/A08049-08068.pdf 
80 , los ejemplares de algunas editoriales presentaban, en un intento de hacer los contenidos más comprensibles para el alumnado (López Facal, 1997).

No obstante, comienzan a aparecer algunos síntomas claros de modernización, como la aparición de grupos de innovación metodológica (Sallés y Santacana, 2016), la creación de los Institutos de Ciencias de la Educación (1969) y los Centros de Profesores (CEP, ya en 1984) a imagen de los Teachers' Centres británicos y norteamericanos (Luis y Romero, 2009, p. 242).

Este espíritu renovador cristalizará en una nueva ley de Educación, la Ley Orgánica General del Sistema Educativo', promulgada en 1990 con voluntad de revolucionar las formas y fórmulas de enseñanza.

En el Real Decreto de enseñanzas mínimas ${ }^{10}$, y en el campo concreto de la historia, el listado de procedimientos integrados en los tres ejes (tratamiento de la información, explicación multicausal e indagación e investigación) que articulan los contenidos establecidos en la materia de la ESO, ahora denominada Ciencias Sociales, Geografía e Historia, constituyen todo un abanico de posibilidades metodológicas.

No obstante, resulta un tanto sorprendente que no encontramos directrices explicitas de cómo enseñar ni en la Ley Orgánica, ni en el Real decreto de enseñanzas mínimas. Para encontrar consideraciones metodológicas explicitas, debemos acudir al Real Decreto que establece el currículo para las Comunidades Autónomas que todavía entonces no tenían competencias transferidas, lo que se conocía como "territorio MEC»"

Es en este texto donde se desarrolla un apartado completo denominado "Orientaciones metodológicas», en el que se señala que, al tratarse de un currículo abierto, los métodos de enseñanza son responsabilidad del profesor, si bien se indican unos principios pedagógicos, válidos para todas las áreas y que, efectivamente, bien pueden aplicarse a la enseñanza de las Ciencias Sociales. Como punto de parti$\mathrm{da}$, se identifica al alumno como el verdadero agente de sus aprendizajes, debiendo actuar el profesor como mediador entre las ideas previas y los nuevos contenidos, propiciando oportunidades para ponerlos en práctica. Se enfatiza en la utilidad que deben tener los aprendizajes, garantizando que los contenidos procedimentales se apliquen en contextos diversos, de manera que los estudiantes adquieran autonomía en el acceso al conocimiento (aprender a aprender). Y se insiste en que debe

${ }^{9}$ Ley Orgánica 1/1990, de 3 de octubre, de Ordenación General del Sistema Educativo. BOE n.o 238 (4/10/1990). https://www.boe.es/boe/dias/1990/10/04/pdfs/A28927-28942.pdf

10 Real Decreto 1007/1991, de 14 de junio, por el que se establecen las enseñanzas mínimas correspondientes a la Educación Secundaria Obligatoria. BOE n.o 152 (26/06/1991). https:// www.boe.es/buscar/doc.php?id=BOE-A-1991-16422\#top

11 Anexo al Real Decreto 1345/1991, de 6 de septiembre, por el que se establece el currículo de la Educación Secundaria Obligatoria. https://www.boe.es/boe/dias/1991/09/13/ pdfs/C00039-00094.pdf 
prestarse gran atención a los aspectos prácticos «a los que tradicionalmente se ha reservado un espacio muy reducido y marginal en el currículo escolar», para lo cual se deben manejar una amplitud de recursos de variada índole, atendiendo a la diversidad del alumnado en el interior del grupo de clase.

La implantación de la LOGSE se vio acompañada de un gran esfuerzo formativo, canalizado fundamentalmente a través de un amplio abanico de cursos de actualización pedagógica diseñados por los CEP. Como sostiene Andrés Rubia (2012), la formación permanente se convirtió en una obligación para el profesorado, que permitirá a la Administración educativa formarle en las exigencias de la reforma, compensándoles con un complemento económico en función de su participación (sexenios).

\subsection{El galopar legislativo y su repercusión en la enseñanza de las Ciencias Sociales (del 2000-2002 al 2020)}

Diez años después de la implantación de la LOGSE, en el año 2000, estando en el poder el Partido Popular (conservador), el Ministerio de Educación publicó un nuevo Decreto de Enseñanzas Mínimas que enmendaba, sin tocarla, la filosofía curricular de la LOGSE, secuenciando los contenidos por cursos ${ }^{12}$. En relación con los aspectos metodológicos, en el posterior desarrollo curricular establecido para el territorio $\mathrm{MEC}^{13}$, se dice explícitamente en la introducción a la materia, ahora denominada Geografía e Historia, que «si bien los métodos de enseñanza se inscriben dentro de la responsabilidad propia del profesor parece razonable, a la hora de expresar este diseño educativo, hacer ciertas referencias a determinadas preocupaciones didácticas».

Así, en el caso de la geografía, se recomienda que en los primeros cursos se utilice un enfoque observacional y descriptivo de los procesos, acompañado de mapas, imágenes, textos y datos estadísticos para, en el segundo ciclo, ser capaces de analizar y explicar fenómenos complejos mediante datos cualitativos y cuantitativos, acompañados, en la medida de lo posible, de salidas de campo. En el caso de la historia, se aconseja el «uso de información básica, extraída de textos historiográficos e históricos, breves y sencillos, imágenes, mapas, estadísticas o noticias de prensa, teniendo siempre presente las características propias de cada edad». El

12 Real Decreto 3473/2000, de 29 de diciembre, por el que se modifica el Real Decreto 1007/1991, de 14 de junio, por el que se establecen las enseñanzas mínimas correspondientes a la educación secundaria obligatoria. BOE n.o 14 (16/01/2001). https://www.boe.es/boe/ dias/2001/01/16/pdfs/A01810-01858.pdf

${ }^{13}$ Real Decreto 937/2001, de 3 de agosto, por el que se modifica el Real Decreto 1345/1991, de 6 de septiembre, modificado por el Real Decreto 1390/1995, de 4 de agosto, por el que se establece el currículo de la Educación Secundaria Obligatoria. BOE n.o 215 (7/09/2001). https:// www.boe.es/boe/dias/2001/09/07/pdfs/A33733-33795.pdf 
trabajo con estas fuentes se debe complementar con actividades de cine y televisión, se menciona por primera vez el uso de las nuevas tecnologías, y la necesidad de realizar ejes y frisos cronológicos, todo ello con la finalidad de «crear en el alumno una conciencia vinculada al pasado que le permita comprender el presente y lo prepare para su proyección hacia el futuro».

Un año y medio después de la publicación de este Real decreto, en diciembre del 2002, ve la luz una nueva ley general educativa, la Ley Orgánica para la Calidad de la Educación (LOCE) ${ }^{14}$. La segunda legislatura del Partido Popular, con mayoría absoluta, anima al gobierno de José M.a Aznar a finiquitar definitivamente «el espíritu LOGSE». La regulación de las enseñanzas de la Educación Secundaria Obligatoria de la nueva ley, desplegadas en un nuevo Real decreto de Mínimos ${ }^{15}$ y un Real decreto del currículo ${ }^{16}$ para el territorio MEC (ya reducido exclusivamente a Ceuta, Melilla y los centros en el extranjero), al menos en lo que a la materia de Geografía e Historia se refiere, son copia casi literal de los ya publicados en el 2000 y el 2001, por lo que nada nuevo se dice en ellos. Y aunque vieron la luz en el Boletín Oficial del Estado, su aplicación quedó paralizada en el 2004, con la llegada al poder de PSOE de Rodríguez Zapatero.

Suspendida la aplicación de la LOCE, pero conscientes de la problemática generada por la LOGSE, muy contestada por una parte importante del profesorado ante la creciente burocratización del currículo (Taínta, 2007), el Ministerio de Educación trabaja en un nueva ley educativa que finalmente verá la luz el 3 de mayo de 2006, la Ley Orgánica de Educación (LOE). ${ }^{17}$ En relación con nuestros intereses, esta norma presenta dos novedades, una de ellas de gran calado. Por un lado, es la primera vez que una ley orgánica incluye un apartado de «Principios pedagógicos» para la educación secundaria, donde se recogen, como su propio nombre indica, postulados generales sobre cómo se ha de articular la acción docente (atención a la diversidad, respeto por los ritmos diferentes de aprendizaje, fomento del hábito lector, etc.). Por otro, se incluye las competencias básicas como un componente más del

14 Ley Orgánica 10/2002, de 23 de diciembre, de Calidad de la Educación. BOE n. 307 (24/12/2002) https://www.boe.es/boe/dias/2002/12/24/pdfs/A45188-45220.pdf

${ }_{15}$ Real Decreto 831/2003, de 27 de junio, por el que se establece la ordenación general y las enseñanzas comunes de la Educación Secundaria Obligatoria. BOE n. 158 (3/07/2003) https:// www.boe.es/boe/dias/2003/07/03/pdfs/A25683-25743.pdf

16 Real Decreto 116/2004, de 23 de enero, por el que se desarrolla la ordenación y se establece el currículo de la Educación Secundaria Obligatoria. BOE n. 35 (10/02/2004) https:// www.boe.es/boe/dias/2004/02/10/pdfs/A05712-05791.pdf

17 Ley Orgánica 2/2006, de 3 de mayo, de Educación. BOE n.o 106 (4/05/2006) https://www. boe.es/buscar/pdf/2006/BOE-A-2006-7899-consolidado.pdf 
currículo ${ }^{18}$, que quedarán fijadas en el Real decreto de enseñanza mínimas ${ }^{19}$, donde se les adjudica, en relación con la metodología docente, la función de "orientar la enseñanza, al permitir identificar los contenidos y los criterios de evaluación que tienen carácter imprescindible y, en general, inspirar las distintas decisiones relativas al proceso de enseñanza y de aprendizaje».

En nuestro ámbito, la ley retoma la denominación de ciencias sociales, pero sin abandonar en el título de la materia la geografía y la historia, quedando configurado cómo Ciencias Sociales, Geografía e Historia. Aparece un primer bloque de contenidos donde, ahora, se agrupan los aspectos prácticos o procedimentales. También, como novedad, el Decreto de Mínimos dedica un amplio apartado a señalar las principales contribuciones de la materia a la adquisición de las competencias clave, que no se reducen exclusivamente a la competencia social y ciudadana o a la cultural y artística.

En síntesis, una vez más, podemos comprobar que la propia normativa concede espacio al trabajo activo en las aulas de ciencias sociales y anima a los profesores a integrarlo en sus programaciones.

Seis años después de la aprobación de la LOE, en 2013, una nueva mayoría absoluta de los conservadores propicia la aprobación de una nueva ley general de educación, la Ley Orgánica para la Mejora de la Calidad de la Educación (LOMCE) ${ }^{20}$. La principal aportación de esta norma a la enseñanza de las materias, en nuestro caso denominada de nuevo Geografía e Historia como en la LOCE, radica en la inclusión entre los elementos del currículo de los estándares de aprendizaje o especificaciones de los criterios de evaluación que concretan lo que el alumnado debe saber, comprender y saber hacer en cada asignatura. Como se recoge en el Real decreto del currículo, deben ser observables, medibles y evaluables y permitir graduar el rendimiento o logro alcanzado por los estudiantes, con la finalidad de permitir pruebas estandarizadas ${ }^{21}$. En el caso de la historia van desde descripciones de logros muy concretas y operativas como realizar un eje cronológico, hasta

${ }^{18}$ Recordemos que las competencias básicas fijadas por la LOE son siete: comunicación lingüística, competencia matemática, competencia en el conocimiento e interacción con el medio físico, tratamiento de la información y competencia digital, competencia social y ciudadana, competencia cultural y artística, competencia para aprender a aprender y autonomía e iniciativa personal.

19 Real Decreto 1631/2006, de 29 de diciembre, por el que se establecen las enseñanzas mínimas correspondientes a la Educación Secundaria Obligatoria. BOE n.o 5 (5/01/2007) https:// www.boe.es/eli/es/rd/2006/12/29/1631

${ }^{20}$ Ley Orgánica 8/2013, de 9 de diciembre, para la mejora de la calidad educativa. BOE n.o 295 (10/12/2013) https://www.boe.es/boe/dias/2013/12/10/pdfs/BOE-A-2013-12886.pdf

${ }^{21}$ Real Decreto 1105/2014, de 26 de diciembre, por el que se establece el currículo básico de la Educación Secundaria Obligatoria y del Bachillerato. BOE n.ㅇ 3 (3/01/2015) https://www. boe.es/boe/dias/2015/01/03/pdfs/BOE-A-2015-37.pdf 
descripciones de capacidades complejas como puede ser discutir cómo se entiende en España y en Europa el concepto de memoria histórica (Trepat, 2015). Fuertemente cuestionados por ser elementos que condicionan la acción docente (López Facal, 2014), por su mala redacción (Trepat, 2015) o por su falta de jerarquización, orden y concreción (Monteagudo y López Facal, 2018), también pueden ser entendidos como una herramienta útil, siempre que estén bien diseñados y conciten un amplio consenso (Fuster, 2015).

En cualquier caso, sus días de vida en la normativa estatal están contados porque, como informábamos al inicio de estas líneas, una nueva ley orgánica ha sido recientemente aprobada, la Ley Orgánica 3/2020, de 29 de diciembre, por la que se modifica la Ley Orgánica 2/2006, de 3 de mayo, de Educación (LOMLOE) ${ }^{22}$ y entre los elementos que definen su currículo, no se encuentran los estándares de aprendizaje, si bien se mantienen las pruebas diagnósticas de evaluación.

\subsection{Muchas reformas, ¿pocos resultados? La percepción de alumnos y docentes}

En los apartados anteriores se han descrito las recomendaciones metodológicas contenidas en los diferentes marcos legislativos, poniendo en evidencia que desde 1970, en mayor o menor medida y a través de diferentes fórmulas, se ha orientado al profesorado de historia y ciencias sociales a asumir planteamientos innovadores encaminados a conferir mayor practicidad a su acción docente. Pero ¿realmente esto ha sido así? No olvidemos que, como afirma Pagès (2009), los cambios curriculares y los cambios en la práctica obedecen a razones diferentes, siendo estos últimos difíciles de interpretar. Y es que, los principios pedagógicos no se pueden desvincular de otros aspectos educativos como la formación del profesorado o la extensión de los contenidos del currículo. Si estos últimos siguen teniendo un carácter enciclopédico y las evaluaciones siguen ancladas en el examen tradicional asociado a contenidos conceptuales y factuales (Gómez y Miralles, 2015), los principios y orientaciones metodológicas se convertirán «en papel mojado», es decir en un cúmulo de buenas intenciones sin proyección real en las aulas de secundaria.

Desde este punto de vista, se ha considerado interesante analizar las visiones de los profesores de Ciencias Sociales en formación sobre los métodos de enseñanza recibidos, indagando en el pasado disciplinar a través de su memoria escolar. Partimos de la idea de que, pese a los sucesivos cambios legislativos y las orientaciones metodológicas propiciatorias del aprendizaje activo contenidas en ellas, la imagen mental de haber cursado una materia fundamentalmente memorística será predominante entre los profesores en formación.

22 Ley Orgánica 3/2020, de 29 de diciembre, por la que se modifica la Ley Orgánica 2/2006, de 3 de mayo, de Educación. BOE n.o 340 (30/12/2020) https://www.boe.es/boe/dias/2020/12/30/ pdfs/BOE-A-2020-17264.pdf 
No es ninguna novedad usar las percepciones y recuerdos del profesorado en activo o en formación, e incluso del alumnado, como fuente para analizar distintos aspectos del proceso de enseñanza-aprendizaje en las diferentes materias de Secundaria (Borrachero et al., 2013). En el caso de la enseñanza de la historia, uno de los primeros autores en utilizar las concepciones del profesorado fue Ronald W. Evans, cuyo trabajo de 1989 ha servido de referencia a numerosos estudios posteriores. Centrados en el caso español, contamos con numerosos trabajos que se han interesado por conocer los recuerdos, percepciones, ideología o concepciones de distintos agentes implicados en la enseñanza o el aprendizaje de contenidos propios de ciencias sociales, a fin de intentar analizar aspectos tales como la metodología docente utilizada por el profesorado para la enseñanza de la historia, la geografía o la historia del arte, las concepciones epistemológicas sobre las disciplinas científicas de referencia, las percepciones sobre la utilidad de recursos varios como las TIC o el patrimonio para la enseñanza de contenidos históricos o geográficos. Los ejemplos son numerosos.

Si nos centramos en el profesorado en activo como fuente de información, podemos citar trabajos como el de Carmen Guimerá (1992), que analizó, a través de un amplio cuestionario, el pensamiento que, sobre su actividad profesional, tenían 114 profesores de historia de Secundaria y Bachillerato; o el más reciente de Molina y Ortuño (2017), en el que se analiza, a partir de las respuestas dadas a un cuestionario por más de 300 profesores de Educación Secundaria de distintos países iberoamericanos, las concepciones que estos tienen sobre el patrimonio como herramienta para lograr el desarrollo del pensamiento histórico del alumnado. Las percepciones del alumnado de Secundaria también han sido analizadas: Trigueros et al. (2015) analizaron las respuestas dadas por 1100 alumnos de distintos institutos de Secundaria de Murcia sobre cuestiones relacionadas con la evaluación y el desarrollo de las competencias históricas. El alumnado universitario también ha servido de fuente de información: Martínez et al. (2006) analizaron los recuerdos de más de 1500 estudiantes de las titulaciones de Magisterio de la Universidad de Murcia sobre su etapa como discentes de las asignaturas de historia de BUP y COU entre 1992 y 2002, para intentar conocer la metodología docente de quienes habían sido sus profesores. Parra (2013), analiza los recuerdos, recogidos por medio de entrevistas, de cuarenta personas que estudiaron tercero de BUP en la provincia de Castellón en la década de 1990, para conocer su experiencia escolar y las repercusiones que esta tuvo sobre su percepción de la historia como materia escolar y formativa. Los recuerdos de los futuros maestros de Educación Primaria sobre su etapa como alumnos de ciencias sociales han sido utilizados tanto para conocer sus concepciones epistemológicas sobre la historia como disciplina escolar y la metodología docente de sus profesores (Gómez et al., 2018), como para conocer la concepción que tienen de la historia como instrumento para lograr la formación cívica del alumnado de Educación Primaria (Molina et al., 2013). 
Por último, los recuerdos y concepciones del profesorado de Educación Secundaria en formación también han sido objeto de estudio: Gómez et al. (2020) han realizado un estudio en el que, a partir de las respuestas dadas por 129 estudiantes del Máster de Formación del Profesorado de cuatro universidades españolas, analizan la metodología docente utilizada por sus profesores de historia, y sus opiniones sobre la utilidad de los recursos digitales para la enseñanza de esta disciplina. Por su parte, López-Castelló (2021), ha analizado, por medio de un cuestionario, los recuerdos de 65 estudiantes del mismo Máster de la Universidad de Valencia sobre la manera en la que recibieron la materia de Historia del Arte en Secundaria.

Estos y otros estudios de índole parecida muestran la importancia que se otorga, en la investigación educativa, a los recuerdos, opiniones y concepciones de alumnado y profesorado, pese a su más que clara y destacada carga subjetiva. Pero, además, todos estos estudios nos permiten contar con un amplio elemento comparativo, que abarca desde la década de los años ochenta hasta la actualidad, con el que contextualizar y cotejar los datos que hemos obtenido en este trabajo, y con ello, poder comprobar si las sucesivas reformas legislativas supusieron auténticas mejoras en la enseñanza de las ciencias sociales.

\section{MARCO EMPÍRICO}

\subsection{Diseño de la investigación}

En consecuencia con lo expuesto en el apartado anterior, el objetivo fundamental de esta investigación ha consistido en indagar en los recuerdos y concepciones del futuro profesorado de ciencias sociales sobre los métodos docentes desarrollados en su materia durante su escolaridad obligatoria, e identificar, si las hubiere, diferencias en función del marco legislativo vigente en ese momento.

El estudio se ha realizado en las Universidades de Murcia y Valladolid, en la especialidad de Geografía e Historia del Máster de Formación de Profesorado ${ }^{23}$, durante el curso académico 2020/2021. La muestra total está constituida por 54 participantes ( $n=54), 20$ de la Universidad de Valladolid y 34 de la Universidad de Murcia.

Por sexos, hay una pequeña desviación a favor de los hombres: 30 cuestionarios (55\%) frente a 24 respondidos por mujeres ( $45 \%$ del total). La totalidad de los participantes son graduados (es decir, no han cursado licenciaturas), y la mayor

23 En la Universidad de Murcia se denomina «Máster Universitario en Formación del Profesorado de Educación Secundaria Obligatoria y Bachillerato, Formación Profesional, Enseñanzas de Idiomas y Enseñanzas Artísticas» y en la Universidad de Valladolid "Máster en Profesor de ESO y Bachillerato, Formación Profesional y Enseñanza de Idiomas». Para facilitar la lectura, a lo largo de este artículo, se ha optado por denominarlo como «Máster de Formación del Profesorado». 
parte (39 de los 54, esto es, el $72 \%$ ) han finalizado sus grados universitarios entre 2018 y 2020. El resto, 15 participantes, terminaron sus estudios entre 2010 y 2013 (cinco casos), y 2015 y 2017 (diez casos). En función de su edad, 15 cursaron sus estudios de ESO con el currículo de la reforma del 2000 y 36 con el currículo de la LOE. Otros 3 no la indican.

En cuanto a la formación que les ha servido para cursar el máster, se observa una clara predominancia por el grado de Historia: 39 de los participantes (72\% del total) son graduados en Historia, frente a 10 graduados en Historia del Arte (18\% del total) y solo 5 graduados en Geografía ( $9 \%$ del total). Esta proporción es consecuente con la población de alumnado matriculado en estos tres grados universitarios.

Por último, resulta interesante destacar que el $91 \%$ de los participantes (49 de los 55) estudian el Máster de Formación de Profesorado en la misma universidad (Valladolid o Murcia) en la que realizaron el Grado. Los cinco participantes restantes proceden de las universidades de Sevilla, Salamanca, Granada, Zaragoza y Autónoma de Barcelona.

En esta investigación el diseño empleado ha tenido un enfoque cualitativo, ya que siguiendo a autores como Albert (2007) o Vallejos (2008), se puede considerar el más indicado para comprender las motivaciones y percepciones de los individuos. Se trata de un diseño de investigación asimilable a los de corte descriptivo (Bisquerra, 2012), en tanto que se busca definir percepciones que los participantes tienen sobre su experiencia como discentes, centrado en el análisis de contenido. Todo contenido de un texto o una imagen puede ser interpretado de una forma directa y manifiesta o de una forma soterrada de su sentido latente (Andreu, 2002). Por tanto, aceptamos que el lenguaje es la punta del iceberg que oculta un vasto conjunto de conocimiento socialmente construido e información culturalmente compartida (Strauss y Feiz, 2014; Van Dijk, 2016b; O’Connor, 2019).

La posibilidad de contar con informantes que han recibido instrucción básica durante dos leyes educativas diferentes nos ha de permitir tener una opinión razona$\mathrm{da}$, en tanto que conocen los fundamentos epistemológicos de la disciplina (pues ya poseen estudios superiores en Historia, Geografía o Historia del arte), y que aspiran a dedicarse a la enseñanza. Puesto que se encuentran en un periodo de formación donde tienen conocimiento de estrategias educativas y de técnicas pedagógicas para favorecer el proceso de enseñanza y aprendizaje de la materia, consideramos que el análisis de sus opiniones puede servirnos de pulso acerca del efecto que los cambios normativos están surtiendo sobre la mejora de la enseñanza de las ciencias sociales.

\subsection{Instrumento de recogida de datos y procedimiento de análisis}

Para la obtención de datos se hizo uso de un cuestionario abierto, elaborado ad hoc para un proyecto de investigación más amplio donde se integra el objeto de estudio de este artículo, compuesto por dos bloques de preguntas. El primer 
Tabla 1. Preguntas del segundo bloque del cuestionario utilizado en la investigación Código

Pregunta

¿Para qué crees que sirve enseñar ciencias sociales hoy? En otras palabras, ¿cuál

P1 crees que es la utilidad social de enseñar geografía, historia e historia del arte, qué finalidad debe tener llevar estas disciplinas a las aulas?

En sociedades como la nuestra, en las que la multiculturalidad es un hecho, ¿qué

P2 tipo de ciencias sociales (¿qué historia, qué geografía, qué historia del arte?) crees que se han de enseñar?

En breves líneas, resume las características que, en general, tenía la enseñanza de las ciencias sociales que recibiste en tu escolaridad obligatoria. Puedes diferenciar entre Educación Primaria y Secundaria.

Es habitual encontrarnos con la queja, por parte del alumnado, de que la de ciencias sociales es una materia aburrida porque supone, básicamente, memorizar datos. ¿Cómo crees que debiera plantearse la enseñanza de estas asignaturas para combatir esa visión negativa? ¿por qué enseñar ciencias sociales?

bloque tiene un carácter descriptivo, y está destinado a obtener una serie de variables (sexo, edad, grado cursado, año de finalización del grado, universidad de procedencia) que permita recrear perfiles de referencia a las respuestas obtenidas. El segundo bloque (Tabla 1) está formado por cinco preguntas, en las que se plantean cuestiones relacionadas con la epistemología y la función social de la enseñanza de las ciencias sociales (preguntas P1 y P5); el tipo de contenidos que, en su opinión, debieran llevarse a las aulas de ciencias sociales (pregunta P2); la metodología docente que debiera aplicarse en las clases de historia (pregunta P4); y la pregunta sobre los recuerdos y percepciones que tienen sobre su experiencia como alumnos de la materia de Geografía e Historia durante su escolaridad obligatoria (pregunta $\mathrm{P} 3$ ).

Para la elaboración del instrumento de recogida de datos se han tenido en cuenta tanto las recomendaciones que sobre diseño y validación de cuestionarios se plantean desde ámbitos ajenos al campo educativo (Álvarez, 2003; Sarabia y Alconero, 2019), como los trabajos que, por temática o procedimiento, se encuentran más cercanos al estudio que nos ocupa (Alfageme et al., 2011; Molina et al, 2016). En todo caso, en la creación del cuestionario se ha seguido el proceso ya estandarizado: revisión teórica del tema, preparación de un diseño inicial, validación por grupo de expertos, y elaboración definitiva de la herramienta (Álvarez et al. 2018).

Como principales referentes teóricos utilizados para la elaboración del cuestionario se encuentran los trabajos de Martínez et al. (2006), Parra (2013), Molina et al. (2016), y Molina y Ortuño (2017) todos ellos centrados en concepciones, creencias y recuerdos sobre la enseñanza de las ciencias sociales en educación secundaria. 
En cuanto a las preguntas del primer bloque, siguiendo como modelo, sobre todo, el trabajo de Molina et al. (2016), se opta por crear una reducida batería de preguntas destinadas a conformar los perfiles identificativos de los participantes, sin atentar su anonimato.

En el caso del segundo bloque, los estudios mencionados nos llevan a poder formular, entre otras, la pregunta que nos permite indagar sobre la experiencia que, como alumnos de ciencias sociales, tuvieron los participantes durante su escolarización obligatoria a partir de sus recuerdos, lo que permite realizar una comparativa, principalmente, con el trabajo de Parra (2013), pero también con el de Martínez et al. (2006).

Una vez elaborado el diseño inicial, este es validado por cuatro expertos (dos profesores universitarios de Didáctica de las Ciencias Sociales de la Universidad de Murcia, y dos profesores en activo de Ciencias Sociales de Educación Secundaria de dos centros de la Comunidad Autónoma de la Región de Murcia). En la validación se utiliza como cuestionario de evaluación un modelo de ficha basado en el utilizado en Molina et al. (2016), en torno a categorías de significatividad, precisión y claridad de las preguntas. En dicha validación la respuesta de los expertos es totalmente positiva, por lo que el diseño inicial no se modifica.

Como ya hemos mencionado anteriormente, en este estudio, presentamos solo los resultados obtenidos en una de las cinco preguntas del cuestionario, la P3 (Tabla 1), que está directamente relacionada con los objetivos del estudio que se presenta en este artículo. Las narrativas obtenidas han sido codificadas y procesadas de manera inductiva con el software informático de análisis de datos cualitativo NVivo, lo que nos ha permitido obtener una buena sistemática a partir de un amplio abanico de categorías. Para mantener el anonimato, pero conservar el perfil de los participantes que se ofrece en el primer bloque de preguntas, se asignó a cada cuestionario respondido un código que comienza por la letra $E$ en el caso de los participantes de la Universidad de Murcia, y por $V$ en el caso de los participantes de la Universidad de Valladolid.

\section{ANÁLISIS DE RESULTADOS: LOS RECUERDOS SOBRE LA EXPERIENCIA COMO DISCENTE DE CCSS EN ETAPAS EDUCATIVAS OBLIGATORIAS}

El análisis de la información obtenida nos permite realizar un sondeo sobre qué tipo de enseñanza se viene llevando a cabo en las últimas décadas, y en qué medida puede haber una correlación entre lo que se ha experimentado y lo que los docentes en formación estiman pertinente para la enseñanza de la historia. Así mismo, y tal como reconoce el caso E33, puede influir el modo en el que se ha recibido la enseñanza de las ciencias sociales en la futura labor docente a desempeñar: 


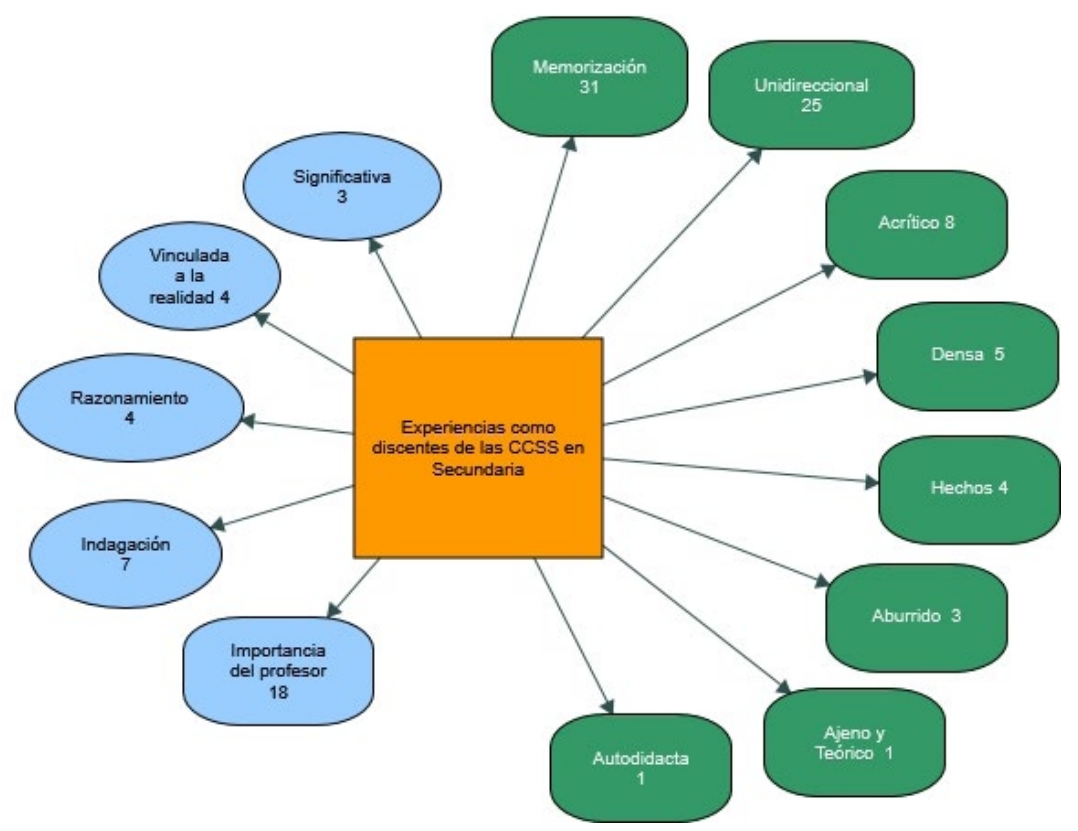

Figura 1. Relación de códigos y frecuencia en los casos para el objetivo 1

Como dije antes, diferenciar a la hora de impartir las ciencias sociales puede ser negativo para el aprendizaje del alumno, quizás sea por la formación que he recibido que mi opinión sea similar a las experiencias que he vivido. (E33)

La primera tarea, una vez obtenidos los datos, fue categorizar las respuestas obtenidas y cuantificar las frecuencias de las mismas, tal y como puede verse en la Figura 1.

De partida podemos comprobar cómo el número de narraciones que muestran un carácter negativo respecto a la enseñanza de la historia recibida es alto (Figura 1), pues de los 54 casos analizados, 34 recogen aspectos principalmente negativos, y en 15 predominan los aspectos positivos, aunque hay que tener en cuenta que existe la posibilidad de que en una misma narración coincidan aspectos negativos y positivos, especialmente cuando se habla de etapas educativas diferentes (4). Un ejemplo de este tipo de respuestas «duales» se recoge en el cuestionario E14:

Durante la Educación Primaria recuerdo tener una enseñanza de las CCSS más aplicada a la realidad del alumnado, sobre todo con la geografía al poder observar alguno de los conocimientos impartidos. (E14)

O en las que el papel de diferentes docentes provocó diferentes experiencias, caso del cuestionario V54: 
Lo que recuerdo de mi etapa de Secundaria respecto a las ciencias sociales varía mucho en función de los profesores que tuve. Algunos de ellos, sus explicaciones se basaban en estar sentados comentando el libro. Es de ellos de quienes no tengo muchos recuerdos porque no fueron significativos para mí. No obstante, también tuve otros que utilizaban recursos más dinámicos y atractivos (vídeos, juegos, proyectos, etc.). De ellos sí que tengo recuerdos, lo mismo que de sus explicaciones. Es decir, he tenido buenas y «malas» experiencias, y son las buenas las únicas que me aportaron algo. (V54)

Son 10 las narraciones que muestran un tono neutro que no aconsejan decantarlas hacia ningún lado:

Tanto en Primaria como en Secundaria era muy similar. Se basaba en que el profesor impartía la materia mediante el apoyo de los libros de texto. Mandando deberes todos los días, algún trabajo esporádico y la entrega de la libreta de forma periódica para que el docente pudiera corregir y controlar nuestro trabajo a lo largo de las semanas. (E07)

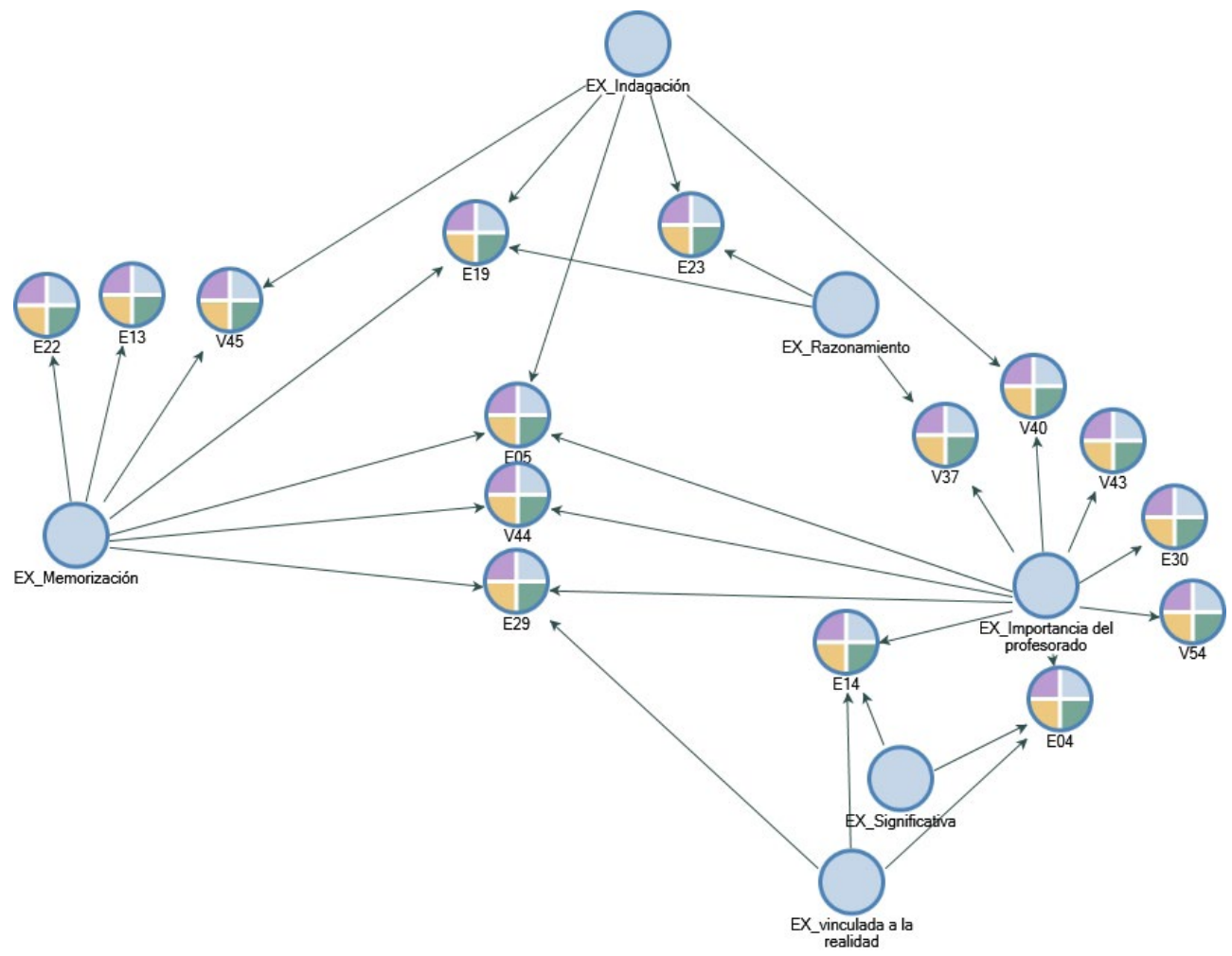

Figura 2. Temas mencionados en los casos que recogen experiencias positivas 
Respecto a las experiencias positivas (Figura 2), comprobamos cómo el papel del profesorado aparece en gran medida relacionado con aspectos importantes de la docencia como son el aprendizaje significativo, la vinculación de la materia con la realidad actual, el razonamiento o las estrategias de indagación. También comprobamos cómo la memoria no es un problema en estas narraciones, ya sea porque simplificaba la labor que han de realizar los estudiantes («incluso al ser asignaturas basadas en la memorización iresultaba fácil aprobar!» -E22-), ya sea porque la memoria no era la única de las habilidades cognitivas que se empleaban en clase. Aunque haya un 27,7 \% de buenos recuerdos sobre la enseñanza de las ciencias sociales, y en especial de la historia, lo cierto y verdad es que el mayor peso se lo llevan las valoraciones negativas sobre cómo han recibido una enseñanza de la historia y de la geografía. Como ya hemos visto, el $62,9 \%$ de los casos analizados muestran su insatisfacción, y lo hacen en torno a una serie de aspectos que podemos ver en la Figura 3. Aquí podemos apreciar la sucesión de temas que se mencionan en los casos y que generan una idea de coherencia en cuanto a la presencia de los mismos.

Dos ideas principales son las que convergen. Aunque la memorización en un $14,81 \%$ del total de los 54 casos no había supuesto un elemento negativo, un 31,4\% sí que lamentan que la habilidad cognitiva más utilizada sea la memorización en lugar del razonamiento, y de que la metodología más habitual haya sido la lección magistral con su carácter unidireccional (un $25,9 \%$ de los casos), lo que se ve com-

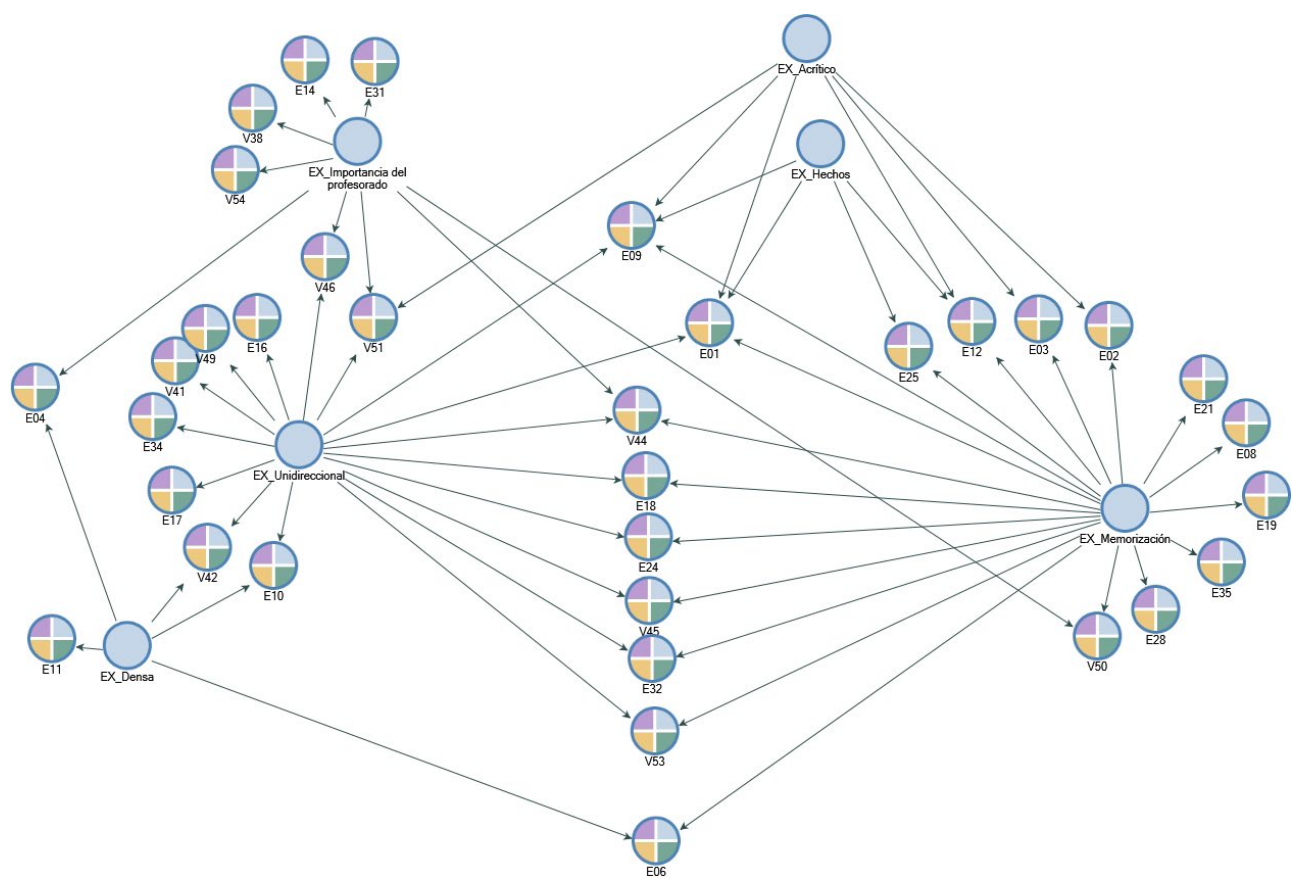

Figura 3. Temas mencionados en los casos que recogen experiencias negativas 
Tabla 2. Casos con menciones positivas y negativas en relación a los temas surgidos durante la codificación

\section{EX_Positivo}

\begin{tabular}{lccc} 
& EX_Positivo & EX_Negativo & EX_Tono neutro \\
\hline EX_Memorización & 3 & 17 & 5 \\
\hline EX_Unidireccional & 1 & 14 & 6 \\
\hline EX_Acrítico & 0 & 6 & 0 \\
\hline $\begin{array}{l}\text { EX_Importancia del } \\
\text { profesorado }\end{array}$ & 10 & 6 & 1 \\
\hline EX_Significativa & 2 & 0 & 0 \\
\hline EX_Densa & 0 & 3 & 0 \\
\hline EX_Hechos & 0 & 4 & 0 \\
\hline EX_Vinculada a la realidad & 3 & 0 & 0 \\
\hline EX_Indagación & 5 & 0 & 2 \\
\hline EX_Razonamiento & 3 & 0 & 1 \\
\hline EX_Aburrido & 0 & 3 & 0 \\
\hline EX_Ajeno_teórico & 0 & 1 & 0 \\
\hline
\end{tabular}

pletada con elementos como el carácter acrítico, la explicación solo de hechos y el diseño denso de los currículos. Estos elementos no vienen ya determinados porque se yuxtapongan los temas sino en la vinculación de los mismos. Es decir, acudimos a la co-ocurrencia de códigos, y lo que comprobamos es una situación muy similar a la que muestran los temas tratados en las narraciones (Tabla 2).

Otro aspecto interesante creemos que es la valoración que juega la memoria en aquellas narraciones que no lo veían como un problema. El caso E13 afirma:

Recuerdo que disfrutaba mucho la materia y era una de mis favoritas. Personalmente, no me supuso ningún trauma tener profesores que mandaban deberes y nos hacían aprendernos los mapas físicos y políticos, y ninguno de mis profesores usaba metodologías «innovadoras» ni en Primaria ni en Secundaria. (E13)

El caso 29 introduce un matiz interesante, en tanto que parece indicar que la capacidad crítica del alumnado de Secundaria aconseja más la memorización que otras técnicas para facilitar contactar con el alumnado, evitando así explicaciones complejas:

Era un tipo de aprendizaje memorístico, con soporte del libro de texto. Según el docente conseguía que se empatizara más con el contenido, pero sin alcanzar su objetivo. Apenas se incidía en las consecuencias sociales de determinados hechos, con los que es fácil empatizar a esa edad para transmitir. (E29) 
Siguiendo con los aspectos positivos y la correlación de temas, el papel de los profesores a la hora de favorecer el interés del alumnado se muestra como un factor destacable a la hora de marcar la memoria positiva respecto a la materia:

Fue en Bachiller -en donde los contenidos son más cercanos en el tiempo-donde puedo caracterizar positivamente estas materias, bien por lo que suscitaron en mí, bien por el propio carisma de la docente que impartía las asignaturas. (E14)

El papel docente se muestra como el gran conector de aspectos de los elementos positivos remarcados por los casos analizados, ya que sin duda es el gran promotor que se encuentra detrás de favorecer el carácter significativo, el razonamiento y las estrategias de indagación en las clases.

Sin embargo, cuando nos centramos en los aspectos negativos, el papel del profesor también está presente:

En Secundaria recuerdo que depende mucho según el curso que me refiera, pero en general no se me daban mal las ciencias sociales, aunque la mayoría de las veces me parece que el profesor no estaba muy preparado para explicarlas. (V51)

Sin embargo, muy a mi pesar, he de reconocer que en otros grupos no existía tal predisposición. De hecho, tengo amigos que a día de hoy reconocen no recordar nada de la materia en esos años porque quizás la actitud de los profesores respecto al contenido a abordar nunca fue la adecuada. (V46)

En aras a dar sentido a lo que significa negativo para los estudiantes hemos ido un paso más y hemos cruzado dos de los grandes núcleos de temas que aparecían en la Figura 2 (memoria y unidirección) con la Tabla 3 (co-ocurrencia de códigos), y lo que nos muestra es el gran impacto que posee tanto la memoria como el carácter unidireccional del papel del profesor en las clases.

Tabla 3. Co-ocurrencia de códigos en citas que muestran experiencias negativas en función de la presencia de la memoria y del carácter unidireccional de las clases.

\begin{tabular}{|c|c|c|c|}
\hline & & $\begin{array}{l}\text { - Experiencias propias:EX_Memorización } \\
\text { (4) } 32\end{array}$ & $\begin{array}{l}\text { - Experiencias propias:.:EX_Unidireccional } \\
\text { (-) } 25\end{array}$ \\
\hline - Experiencias propias:EX_Densa & (3) 5 & $1(0,03)$ & $1(0,03)$ \\
\hline - Experiencias propias:.EX_Hechos & (4) 4 & $4(0,13)$ & $1(0,04)$ \\
\hline - Experiencias propias:EX_Memorización & (3) 32 & & $8(0,16)$ \\
\hline - Experiencias propias:EX_Negativo & (2.) 41 & $18(0,33)$ & $15(0,29)$ \\
\hline - Experiencias propias:EX_Unidireccional & (3) 25 & $8(0,16)$ & \\
\hline
\end{tabular}


Podemos apreciar claramente cómo la memorización está considerada en gran medida el elemento más peyorativo, ya que más de la mitad de los casos que hablan de experiencias negativas lo vinculan con la memoria:

Una enseñanza de las ciencias sociales muy lineal y que se limitaba a exigir del alumno el memorizar conceptos y expulsarlos en el examen. Se priorizaba más el método clásico que la comprensión por parte del alumnado. (E03)

Si bien la memoria, como ya hemos indicado, no necesariamente lleva implícita una carga negativa, lo cierto es que de los 27 casos que hablan de la memorización en las clases recibidas, 17 lo han vinculado de forma negativa, lo que indica la fuerza de la asociación entre memoria y elemento negativo, mucha más aún que entre elementos negativos y memoria (17 casos de 34). Así mismo, también suscita negativas el hecho de que abusar de la memorización como habilidad cognitiva implicaba la metodología de la clase magistral o unidireccional, lo cual se traducía en el fomento del carácter acrítico del alumnado:

Memorización pura de hechos históricos fechas, acontecimientos... Poca profundidad de los contenidos, así como monopolio de la transmisión de ésta de forma exclusiva por los libros de texto que dificultad la capacidad reflexiva e investigadora de los estudiantes. (E09)

En definitiva, podemos apreciar en el siguiente dendrograma (Figura 4) cómo las experiencias vividas por el alumnado en su etapa de discentes de Secundaria reflejan una polarización entre quienes tuvieron unas clases de ciencias sociales atractivas basadas en el uso del razonamiento a través de estrategias de indagación, y aquellos que de forma mayoritaria han expresado su descontento por el hecho de basar las clases en la memorización de los datos y sentirse ajenos al proceso de generación de conocimiento.

Llegados a este punto, y retomando las ideas expresadas con anterioridad sobre el papel que las diferentes leyes pudieran haber jugado a la hora de mejorar la enseñanza de las ciencias sociales, hemos analizado si la visión positiva o negativa pudiera estar condicionada por el marco legislativo cursado. Teniendo en cuenta el calendario de implantación de la reforma curricular de Pilar del Castillo, realizada antes de la promulgación de la LOCE (entre los años 2002 y 2004), y los de la implantación de la LOE (años 2007-2009), podemos clasificar los estudiantes analizados en dos grupos en función de qué ley educativa regía durante los años en los que cursaron su etapa de Educación Secundaria Obligatoria. Así, tenemos que 15 casos pueden ser adscritos a la reforma de Pilar del Castillo, y 36 a la LOE. Tres estudiantes no rellenaron la información relativa a la edad ni a la finalización de sus estudios. Teniendo en cuenta la presencia de aspectos negativos mencionados en las narra- 


\section{Elementos conglomerados por similitud de palabra}

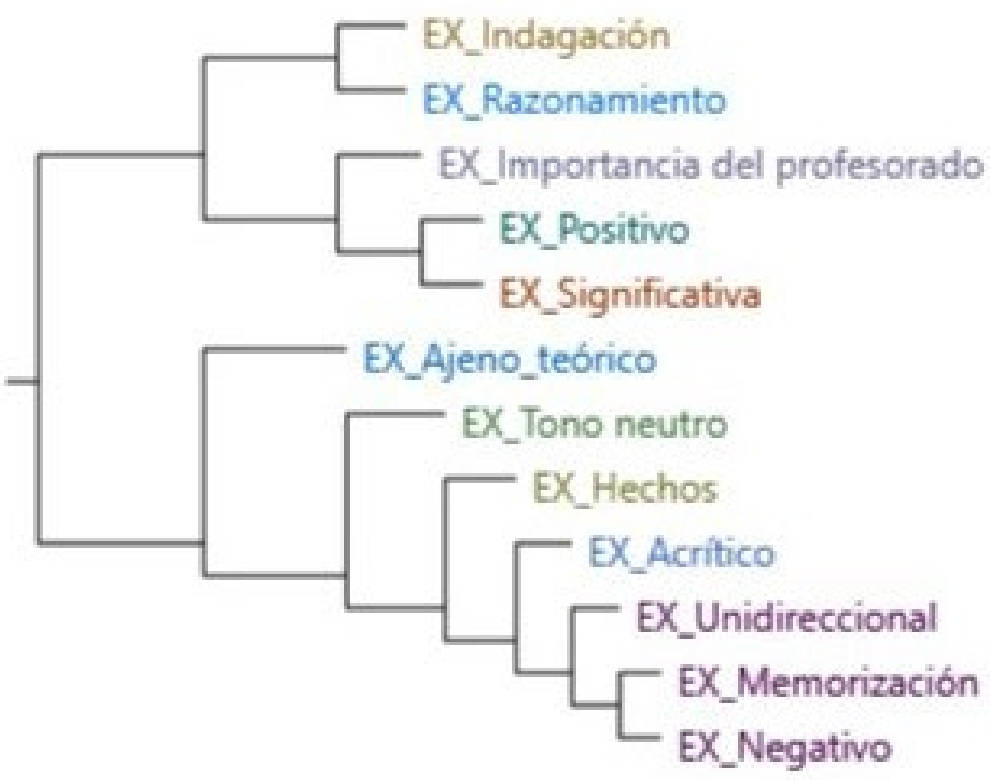

Figura 4. Elementos conglomerados por similitud de palabras

ciones, y de aspectos positivos (dejando al margen los de un tono neutro) podemos comprobar cómo existe un importante repunte de aspectos negativos en los casos de la reforma de Pilar del Castillo, por encima de los mencionados en los casos adscritos a la LOE, quienes junto al carácter negativo y positivo (juntos suman el 77,8\% de los casos), el tono neutro posee una presencia considerable (un 22,2 \%) (Tabla 4). Por otro lado, no se han apreciado diferencias significativas en relación con la universidad ni con el grado universitario cursado por los participantes.

Tabla 4. Porcentaje de menciones negativas y positivas en los casos en función del marco legislativo vigente durante los estudios de ESO

LOE (36)

Pilar del Castillo (15)

Total (51)

\begin{tabular}{lccl}
\hline EX_Negativo & $58,3 \%$ & $80 \%$ & $64,7 \%$ \\
EX_Positivo & $27,8 \%$ & $33,3 \%$ & $29,4 \%$ \\
Total (exclusivo) & $77,8 \%$ & $93,3 \%$ & $82,3 \%$ \\
\hline
\end{tabular}




\section{DISCUSIÓN}

Resulta interesante comprobar que los datos alcanzados en este estudio coinciden plenamente con los obtenidos en trabajos previos. El primer elemento a destacar es que, al igual que en los citados trabajos de Martínez et al. (2006), Parra (2013), y López-Castelló (2021), los participantes guardan, de forma mayoritaria, unos recuerdos negativos de su experiencia como antiguos alumnos de Ciencias Sociales. Es cierto que, al igual que en los casos de Martínez et al. (2006) y Parra (2013), los resultados no muestran una diferencia tan marcada entre recuerdos positivos y negativos como cabría esperar: en el estudio de Martínez et al. (2006), el $51,5 \%$ de los encuestados recuerdan esas clases como «no estimulantes», frente al 42,5 \% que las denominan como «estimulantes»; en el caso de Parra (2013), 22 de los 40 presentaban un recuerdo negativo de la materia, frente a los 18 restantes, que presentaban una imagen positiva. En nuestro estudio de las 54 narrativas, aunque 34 eran claramente negativas, 15 mostraban aspectos principalmente positivos y en 10 de ellas la visión podía clasificarse de «neutra». Este predominio de los recuerdos poco positivos, aunque no muy acusado, resulta muy significativo, y más si tenemos en cuenta que, al igual que en el estudio de López-Castelló (2021), los participantes en nuestra investigación son, presumiblemente, futuros docentes de la materia de Geografía e Historia.

Con todo, lo que resulta realmente interesante es el hecho de que, aunque los participantes de los distintos estudios nos remiten a experiencias educativas que, en algunos casos, están separadas por décadas y hacen mención a marcos legislativos diferentes (desde la LGE en la que cursan sus estudios parte de los participantes en el estudio de Martínez et al. (2006) al currículo LOE, analizado en este trabajo), las razones esgrimidas para justificar esa visión negativa (y también la positiva), son prácticamente las mismas. No obstante, tal como se recoge en el apartado de resultados, en nuestro estudio hemos detectado que sí podría haber alguna relación, aunque muy moderada, entre el marco legislativo y las posibilidades otorgadas a los docentes para introducir elementos de innovación en las clases de geografía e historia, detectándose un cierto avance. No obstante, el diferente tamaño de los dos grupos que componen la muestra no aconseja establecer un significado consistente en cuanto al papel que dicho marco legal pudiera jugar en cuanto a la manera en la que se han enseñado las Ciencias Sociales.

En cualquier caso, y ante el aplastante peso de las visiones negativas sobre la enseñanza de la geografía, la historia y la historia del arte, los participantes en esta investigación señalan como principales puntos negativos de su experiencia como estudiantes en la etapa de Educación Secundaria, en primer lugar la enorme importancia dada a la memorización de datos, en muchos casos relacionados con la propia tipología de evaluación basada en el examen (Monteagudo et al., 2015); en segundo lugar el hecho de que se tratara de una enseñanza unidireccional, en la 
que el rol del alumnado era básicamente pasivo (uso de la exposición y la lección magistral por parte del profesor, alumnado centrado en tomar apuntes); $y$ en tercer lugar, la práctica ausencia del fomento del pensamiento crítico (ausencia de uso de otros materiales distintos al libro de texto, poco o nulo uso del debate...). Son, básicamente, los mismos problemas que recogen Martínez et al. $(2006,61)$ cuando se refieren a las «aburridas» clases de historia desarrolladas entre 1992 y 2002 según los datos recogidos en su estudio: clases monótonas, eternas y exasperantes, poco amenas, pasivas, faltas de expresión, sin método y faltas de diversidad. Parra $(2013,9)$ recoge testimonios en los que los participantes en su estudio, alumnos de BUP en los años noventa, usan términos como memorización, pasividad, aburrimiento, rutina o tradicional. Los resultados de Gómez et al. (2018) y Gómez et al. (2020) muestran que, tanto la memoria discente de los maestros en formación como los del futuro profesorado de Geografía e Historia guarda, mayoritariamente, recuerdos de sus clases de historia basados en preceptos muy tradicionales: lección magistral, dictado de apuntes, uso mayoritario del libro de texto, ausencia de uso de fuentes primarias, uso del examen como principal instrumento de evaluación, exámenes basados en la memorización de contenidos... En el caso particular de las asignaturas o contenidos de Historia del Arte, analizado por López-Castelló (2021, 59), la situación se repite: el tratamiento de los contenidos histórico-artísticos era algo anecdótico, superficial, supeditado a la Historia, y en la que se seguían métodos docentes basados en la transmisión de contenidos, en las que no destacaba en modo alguno el papel activo del alumnado.

\section{CONCLUSIONES}

En síntesis, distintas épocas y comunidades autónomas ( $y$, con ellas, diferentes leyes educativas), pero los problemas detectados son los mismos, a pesar del dato mostrado en este trabajo sobre el impacto algo dispar que dos leyes educativas (reforma de Pilar del Castillo y LOE) han podido tener sobre los recuerdos específicos sobre la materia de Ciencias Sociales en ESO. Esto lleva a pensar que, pese a las orientaciones metodológicas contenidas en ellas, gran parte del problema pueda estar relacionado con los currículos que se han sucedido en las últimas décadas, unos currículos que, en lo sustancial, han variado muy poco y siguen teniendo un carácter enciclopédico y muy alejado del fomento del pensamiento histórico (Molina et al., 2014).

En efecto, como hemos señalado anteriormente, las distintas leyes educativas han sido bastante profusas en recomendaciones metodológicas. La Ley General de Educación (1970) proponía la obtención de información a partir de restos arqueológicos, imágenes y obras de arte, el análisis de documentos históricos, la realización de secuencias temporales de acontecimientos obtenidos a partir de fuentes 
diversas, el establecimiento de relaciones entre obras artísticas, la planificación de sencillas investigaciones, la realización de entrevistas a personas entendidas como fuentes de la historia, la identificación del cambio y la continuidad en los elementos del entorno, etc., son solo algunos ejemplos del elenco de aplicaciones prácticas a desarrollar en las aulas de Secundaria, contenidas en la normativa.

Años más tarde, la LOE (2006) volvía a realizar recomendaciones parecidas: para la historia, la obtención de información de fuentes diversas (iconográficas, arqueológicas, escritas, proporcionadas por las tecnologías de la información, etc.), la localización en el tiempo y en el espacio de los periodos, culturas y civilizaciones y acontecimientos históricos, la representación gráfica de secuencias temporales, la identificación de causas y consecuencias de los hechos históricos y de los procesos de evolución y cambio, la contextualización de las manifestaciones artísticas más relevantes, etc. Y en el caso de la geografía se incide en la lectura e interpretación de imágenes y mapas de diferentes escalas y características, la percepción de la realidad geográfica mediante la observación directa o indirecta y la interpretación de gráficos y elaboración de estos a partir de datos.

El hecho de que tres décadas y media más tarde se sigan haciendo indicaciones parecidas, y que el alumnado que ha cursado las asignaturas derivadas de esas legislaciones educativas sigan manteniendo la misma visión negativa (tal y como han mostrado los estudios de Martínez et al., 2006; Parra, 2013; y López-Castelló, 2021), es buena muestra de que algo no ha funcionado debidamente.

Pero puede que otra parte importante del problema se encuentre en la propia formación del profesorado, un factor muy a tener en cuenta, pues como han señalado en distintas ocasiones los informantes en nuestro estudio (y no se trata de ninguna sorpresa), la labor del profesorado se muestra como un elemento clave, hasta el punto de que buena parte de los buenos recuerdos de las clases de historia se deben a la implicación del profesorado. Entonces la clave parece estar en que este profesorado reciba una buena formación inicial (González Gallego, 2010) y continua que le permita desarrollar todo su potencial educativo, que le muestre cuáles son los métodos, recursos, estrategias y materiales de los que puede hacer un buen uso para enseñar ciencias sociales.

En consecuencia, la solución a los muchos y persistentes problemas que, a tenor de lo mostrado en este y otros estudios, tiene la enseñanza de la historia y las ciencias sociales en España, posiblemente no pase tanto por cambiar las leyes educativas cada cinco años, sino tal vez por apostar por una formación simultánea del profesorado (en la que converjan las enseñanzas disciplinares con las didácticas) y no una consecutiva (grado disciplinar y máster en Educación) como la actual (Barberá, 2010), que a todas luces no ha supuesto un cambio trascendental en la enseñanza de la historia y la geografía. 


\section{REFERENCIAS BIBLIOGRÁFICAS}

Albert, M. J. (2007). La investigación educativa: claves teóricas. Mc GrawHill.

Alfageme, M. B., Miralles, P. y Monteagudo, J. (2011). Diseño y validación de un instrumento sobre evaluación de la geografía y la historia en Educación Secundaria. Enseñanza de las ciencias sociales: revista de investigación, 10, pp. 51-64.

Álvarez, R. (2003). Las preguntas de respuesta abierta y cerrada en los cuestionarios. Análisis estadístico de la información. Metodología de Encuestas, 5(1), pp. 4554

Álvarez, O., Sureda, J. y Comas, R. (2018). Diseño y validación de un cuestionario para evaluar la alfabetización ambiental del profesorado de primaria en formación inicial. Profesorado 22(2), pp. 309-328. D https://doi.org/10.30827/ profesorado.v22i 2.7725

Andrés Rubia, F. (2012). Los Centros de Profesores: un modelo frustrado de formación permanente. Forum Aragón, 6, pp. 25-31.

Andreu, J. (2002). Las técnicas de análisis de contenido. Una revisión actualizada. Fundación de Centros de Estudios Andaluces.

Barberá, O. (2010). De nuevo la formación consecutiva y de nuevo el menosprecio a la formación simultánea. En I. González (coord.), El nuevo profesor de Secundaria: la formación inicial docente en el marco del Espacio Europeo de Educación Superior (pp. 89-96). Graó.

Bisquerra, R. (coord.). (2012). Metodología de la investigación educativa. La Muralla.

Borrachero, A. B., Costillo, E. y Bermejo, M. L. (2013). El recuerdo de los futuros profesores de secundaria sobre sus profesores de Biología y Geología en educación secundaria. Enseñanza de las ciencias: revista de investigación y experiencias didácticas, número extra, pp. 467-473. https://www.raco.cat/ index.php/Ensenanza/article/view/296290

Evans, R. W. (1989). Teacher conceptions of history. Theory and Research in Social Education, 17, pp. 11-17. https://doi.org/10.1080/00933104.1989.10505590 
Fuster, C. (2015). Los estándares de aprendizaje de la LOMCE: ¿Mejorarán la enseñanza y el aprendizaje de Historia? Revista de Didácticas Específicas, 12, pp. 27-47. https://doi.org/10.15366/didacticas2015.12.002

Gómez, C. J., Chaparro, A., Felices, M. M. y Cózar, R. (2020). Estrategias metodológicas y uso de recursos digitales para la enseñanza de la historia. Análisis de recuerdos y opiniones del profesorado en formación inicial. Aula Abierta, 49(1), pp. 6574. https://doi.org/10.17811/rifie.49.1.2020.65-74

Gómez, C. J., Rodríguez, R. A., y Mirete, M. B. (2016). Percepción de la enseñanza de la historia y concepciones epistemológicas. Una investigación con futuros maestros. Revista Complutense de Educación, 29(1), 237-250. https://doi. org/10.5209/RCED.52233

Gómez, C. y Miralles, P. (2015). ¿Pensar históricamente o memorizar el pasado? La evaluación de los contenidos históricos en la educación obligatoria en España. Revista de Estudios Sociales, 52, pp. 52-68. https://doi.org/10.7440/ res52.2015.04

González Gallego, I. (coord). (2010). El nuevo profesor de Secundaria: la formación inicial docente en el marco del Espacio Europeo de Educación Superior. Graó.

Guimerá, C. (1992). Práctica docente y pensamiento del profesor de historia de Secundaria. Tesis doctoral. Universidad de Barcelona.

López-Castelló, R. (2021). La Historia del Arte escolar en el recuerdo del profesorado de Educación Secundaria en Formación. Revista Complutense de Educación, 32(1), pp. 55-66. https://doi.org/10.5209/rced.68010

López Facal, R. (1997). Libros de texto. Sin novedad. Con-Ciencia Social, 1, pp. 51-76.

López Facal, R. (2014). La LOMCE y la competencia histórica. Ayer. Revista de Historia Contemporánea, 94, pp. 273-285.

Luis, A. y Romero, J. (2009). Reformas educativas y formación permanente del profesorado en la última obra de Julia Varela: memoria y olvido. Profesorado. Revista de curriculum y formación del profesorado, 13(1), pp. 231-295.

Martínez, N., Souto, X. M. y Beltrán, J. (2006). Los profesores de historia y la enseñanza de la historia en España. Una investigación a partir de los recuerdos 
de los alumnos. Enseñanza de las ciencias sociales. Revista de investigación, 5, pp. 55-71.

Molina, S. y Ortuño, J. (2017). Concepciones del profesorado iberoamericano de Secundaria sobre la contribución del patrimonio local al desarrollo del pensamiento histórico. Revista Estudios Pedagógicos, 43(4), pp. 185-202. https://doi.org/10.4067/S0718-07052017000400010

Molina, S., Felices, M. M. y Chaparro, A. (2016). Diseño y validación de un cuestionario para evaluar la concepción y uso del patrimonio por parte del profesorado de Ciencias Sociales de Educación Secundaria. HERMUS, 19, pp. 149-166.

Molina, S., Gómez, C., y Ortuño, J. (2014). History Education Under the New Educational Reform in Spain: New Wine in Old Bottles. History Education Research Journal 12 (2), 122-132. https://doi.org/10.18546/HERJ.12.2.10

Molina, S., Miralles, P., y Ortuño, J. (2013). Concepciones de los futuros maestros de Educación Primaria sobre formación cívica y ciudadana. Educatio Siglo XXI, 31(1), pp. 105-126. https://revistas.um.es/educatio/article/view/175361

Monteagudo, J. y López Facal, R. (2018). Estándares de aprendizaje y evaluación del pensamiento histórico, ¿incompatibles? Análisis de currículos, programaciones, exámenes y opinión de expertos en España. Perfiles educativos, 40(161), pp. 128-146. https://doi.org/10.22201/iisue.24486167e.2018.161.58586

Monteagudo, J., Molina, S. y Miralles, P. (2015). Opiniones sobre evaluación de los profesores de segundo ciclo de ESO de Geografía e Historia en la Región de Murcia. Revista Mexicana de Investigación Educativa, 20(66), pp. 737761. http://www.scielo.org. mx/scielo.php?script=sci_abstract\&pid=S1405$66662015000300004 \& \operatorname{lng}=e s \& n r m=i s 0$

O'Connor, J. (2019). Document Analysis. En M. Lambert y J. L. Belliappa (Eds.), Practical Research Methods in Education (pp. 67-75). Routledge. https://doi. org/10.4324/9781351188395-7

Pagès, J. (2009). Enseñar y aprender ciencias sociales en el siglo XXI: reflexiones casi al final de una década. En AA. VV., Investigación en Educación, Pedagogía y Formación docente (p. 140-154). Universidad Pedagógica Nacional.

Parra, D. (2013). La conceptualización de la Historia escolar y sus implicaciones didácticas. Un estudio a partir del recuerdo de estudiantes de BUP. Didáctica de 
las Ciencias Experimentales y Sociales, 27, pp. 3-21. https://doi.org/10.7203/ DCES.27.2653

Sallés, N. y Santacana, J. (2016). Los grupos de innovación educativa en la Enseñanza de la Historia en España: Análisis póstumo de los resultados de la aplicación del método por descubrimiento y estado de la cuestión de los aprendizajes por descubrimiento. Educatio Siglo XXI, 34(2), pp. 145-166. https://doi. org $/ 10.6018 / \mathrm{j} / 263851$

Sarabia, C. M. yAlconero, R. (2019). Claves para el diseño y validación de cuestionarios en Ciencias de la Salud. Enfermería en Cardiología, 26(77), pp. 69-73.

Strauss, S. y Feiz, P. (2014). Discourse analysis. Putting our Worlds into Words. Routledge. https://doi.org/10.4324/9780203121559

Taínta, P. (2007). Una mirada hacia atrás (LOGSE) y un paso hacia delante (LOE) en la formación del profesorado de ESO. Estudios sobre Educación, 12, pp. 139-163.

Trepat, C. (2015). La Historia en la LOMCE. ESO y Bachillerato. Iber. Didáctica de las Ciencias Sociales, Geografía e Historia, 79, pp. 49-59.

Trigueros, F. J., Ortuño, J. y Molina, S. (2015). La percepción del alumnado de educación secundaria sobre el desarrollo del pensamiento histórico en el proceso evaluador. Revista de Estudios Sociales, 52, pp. 69-86. https://doi. org/10.7440/res52.2015.05

Vallejos, Y. A. (2008). Forma de hacer un diagnóstico en la investigación científica. Perspectiva holística. Teoría y praxis investigativa, 3(2), pp. 11-22.

Van Dijk, T.A. (2016). Análisis crítico del discurso. Revista Austral de Ciencias Sociales, 30, pp. 213-222. https://doi.org/10.4206/rev.austral.cienc.soc.2016.n30-10 